\title{
GIS FOR HEALTH SERVICES
}

\author{
Ahmed Abdelhafiz ${ }^{1,}$, , Mohamad Abdel-Samea ${ }^{2}$ \\ ${ }^{1}$ Civil Eng. Dept., Faculty of Engineering, Assuit University, Egypt \\ ${ }^{2}$ Vice President of Assuit University, Egypt - (Arch. Dept., Faculty of Engineering)
}

Received 17 May 2013, accepted 30 June 2013

\begin{abstract}
Technology controls our life in almost all fields. Health services are one of these fields which are widely affected by the advances in spatial information technology. Spatial information technology includes Geographic Information Systems (GIS), Global Positioning Systems (GPS), remote sensing, and spatial data management. GIS helps planners in planning and monitoring health care facilities. This enables health authorities matching the facility supply with the relevant demand. Utilization of GIS spatial analysis also promotes the standards of health services. That is why health authorities give investment priority to improve health services employing GIS. Other Applications of GIS and GPS in emergency geographic information services and infection control are appeared. Using GIS in planning new health care facility opens multiple issues. These issues are the locality definition, spatial epidemiology, socio- economic status and health status taking into account age and sex variations in the area concerned. In this paper, the existing situation of public health care facilities in Assuit city, Egypt is assessed according to the guidelines of the Ministry of Health and Population in Egypt "MOHP".
\end{abstract}

Keywords: GIS, health care facility, Assessment, Planning, Accessibility and Utilization

\section{Introduction}

Health is a prerequisite for all mankind. Indeed, it is a critical component of individuals' social needs. Equal access to primary healthcare services for low socioeconomic groups is an aim for governments to meet social justice policy agenda. In response to this policy agenda, governments' investments give priority for monitoring and evaluating health care services. It is also essential to plan for more health service facilities and transport for areas which need more attention regarding healthcare. In order to improve the access to public services either on the basis of the spatial distribution of services or on the availability of transport services, studies for assessing existing accessibility problems to health service facilities and transport provision are made (Higgs, 2004).

Analyzing the relationship between location and health facility can assist in controlling and minimizing diseases. It can be also used for better planning with more effective healthcare facility utilization. A large number of studies have shown a regular decline in accessibility to health facilities with increasing distance on road transporting journeys to hospitals. Other studies show variation in maximum distance which people travel to utilize health facilities. It is a general concept that the greater the distance between two points, the lower the probability of these points being functionally related. Adeyemo, 2005 noted that there is a limit to the distance, which people are ready to travel in order to use health services. They further stated that attendance at each medical centre is a function of both type of services available in that medical centre and the distance to other medical centers providing similar service.

\footnotetext{
* Corresponding author.

E-mail address:a.abdelhafiz@yahoo.com
} 
Changes in healthcare needs usually require quick respond from health authorities. So, health authorities are required to make careful analysis about the real demand and supply of health care facilities all over their areas. Finding the best location for a healthcare facility is considered as one of the important health authority tasks in order to optimize resources. Evaluating the accessibility of existing health facilities is also another task carried by health authorities. Health planners detect areas which have poor accessibility for certain health facility. Afterwards, they prepare proposals for improving such low level of health care accessibility. This should ultimately lead to better healthcare outputs and to improve health for everyone.

An important issue is to keep matching health care facilities supply with the relevant demand. This needs huge set of data including health facilities location, catchment areas, population statistics, etc. Advanced information technology in general and Geographical Information Systems GIS in particular help health authorities to mange such huge data sets in an easy and efficient way by processing attribute data and spatial data simultaneously. Therefore, GIS is used to support health planners to reach a decision regarding increasing hospitals capacities in parts of a city with poor healthcare supply. Planners can also use GIS to allocate areas of a city with poor accessibility to hospitals. Accordingly, a decision regarding improving hospital accessibility can be reached. In general, implementing GIS in healthcare planning improves the quality of planning processes in addition to saving time and costs.

In this work, an overview on spatial analysis is given in the next section. Then the role of GIS and its use in health are illustrated. The need for GIS in healthcare service planning and assessment is then enlighten. Local steps made are finally given.

\section{Overview on spatial analysis}

How location can influence health is an old concept in medicine. As far back at the time of Hippocrates (c. 3rd century B.C.), physicians discovered that certain diseases tend to occur in some places and not in others. In fact, different locations on Earth are usually associated with different profiles: physical, biological, environmental, economic, social, cultural and sometimes even spiritual profiles that affect and affected by health, disease and healthcare.

Spatial analysis is used long ago. In 1854 A.C., a major cholera outbreak in London had taken nearly six hundred natives. People believed that the reason of the death is due to the existence of an old cemetery of plague victims. They were convinced that the infection was due to vapours coming from it and they had no idea about the new disease "cholera"!.

Dr John Snow plotted the deaths on a street map. Figure 1 shows a digital recreation of Dr Snow's hand-drawn map. The deaths are displayed as small black circles. Water bumps are displayed in large circles. The grey polygon represents the former burial plot of plague victims. Snow used the map to examine the geographical (spatial) locations of cholera cases in relation to other features on the map (water pumps and cemetery of plague victims). He was actually performing what is now known as spatial analysis.

Journal of Engineering Sciences, Assiut University, Faculty of Engineering, Vol. 41, No. 4, July, 2013,E-mail address: jes@aun.edu.eg 


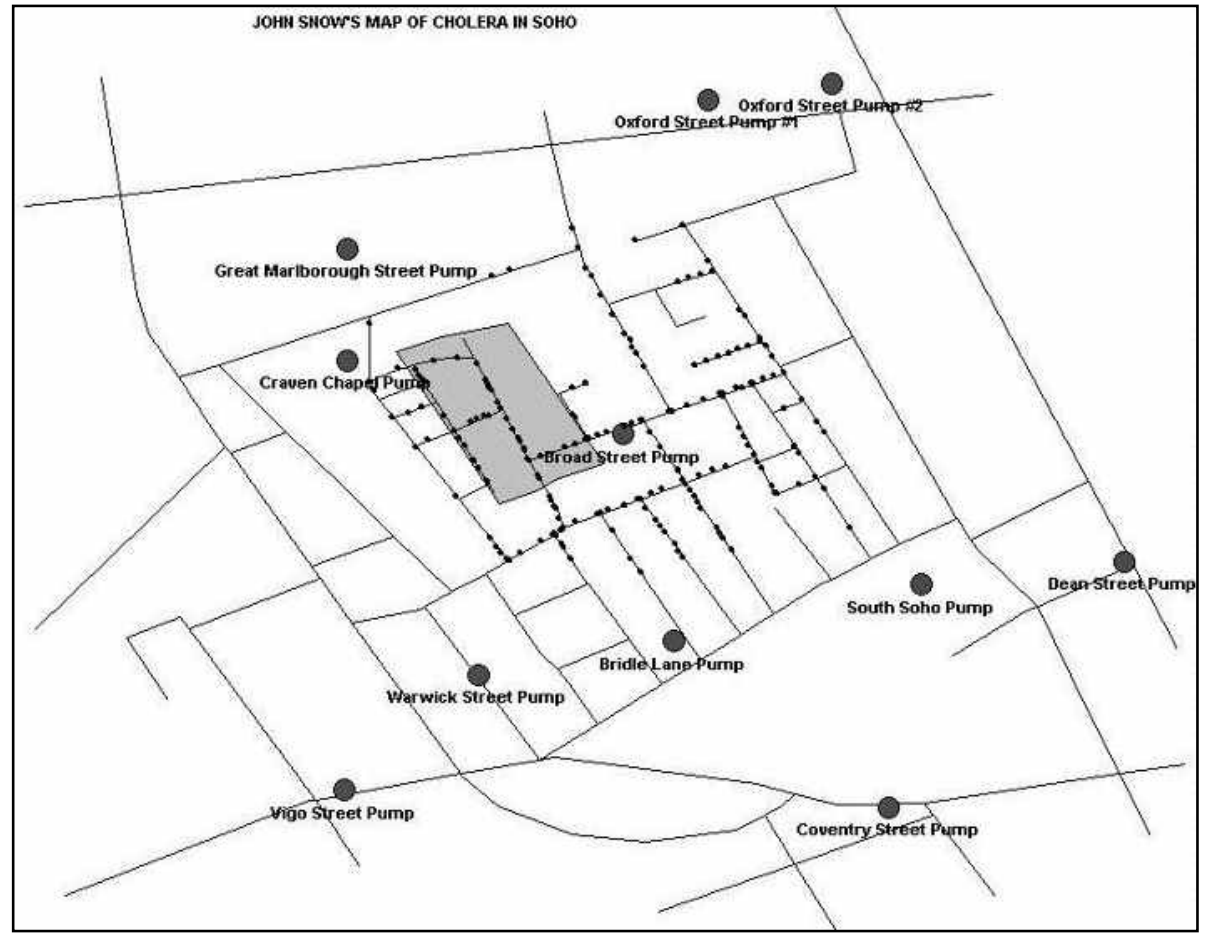

Fig. 1. A digital recreation of Dr Snow's hand-drawn map for cholera deaths in London

From this investigation, he could conclude that there were no relation between the deaths and the old cemetery. He also could prove that the Broad Street pump is a focus of death area. Snow had hypothesised that Broad Street bump (shown in the middle of the map) is a source of contaminated water which is responsible of the death. Dr. Snow recommended that the handle of this pump to be removed. With this action, the outbreak was stopped and he proved that the Broad Street pump was the source of contaminated water. He also proved his theory that the disease "cholera" is transmitted through contaminated drinking water.

Spatial analysis has taken large steps forward in the recent decade. It is indispensable to evaluating patient access to managed care provider networks or modeling demand for services based on the analysis of health and demographic characteristics of patients. Spatial analysis is also indispensable to disease monitoring and management - e.g. the case of SARS and the West Nile virus.

Spatial data infrastructure is important for urban management. Data integration and easy accessing to digital data improve significantly spatial analysis. This promotes the standards of urban management approach (Salamat et al, 2012).

Journal of Engineering Sciences, Assiut University, Faculty of Engineering, Vol. 41, No. 4, July, 2013,E-mail address: jes@aun.edu.eg 


\section{GIS role}

Geographical Information System is a computer system capable of storing, integrating, manipulating, analyzing and displaying data in digital form related to the position of the earth surface (Huang et al, 2001) and (Tang and Zhao, 2000). It consists of five categories which are people, data, software, hardware and methods, see figure 2. GIS development has grown in line with the rapid development of technology during the past decades. It has expressed specific challenges in storage and spatial data analysts. It also functions as an important tool in the process of problem solving and decision making (Reynolds, 2011).

A theme in GIS is a digital map-based technology that relies on database management system that can be used to display information in a separate layer, see figure 2-right. GIS is able to support all the stages of spatial data processing including manual digitizing, checking and editing of digitized data and output of information to graphics devices. Besides that, GIS technology has long been applied in planning activities, which essentially include plans formulation as well as development control (Yaakub et al 2005).
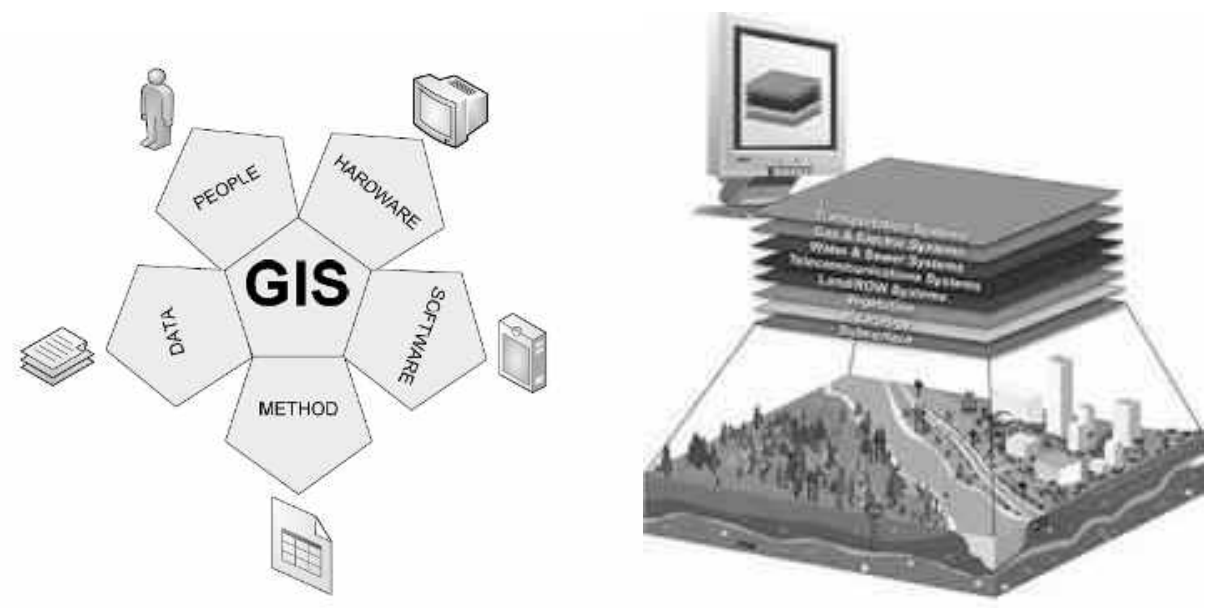

Fig. 2. GIS component and themes (Map World of GIS and Google)

GIS is multidisciplinary by nature, including surveying and mapping, remote sensing, GIS, and the Global Positioning System (GPS). These, in turn, draw from a wide variety of other fields and technologies, including computational geometry, computer graphics, digital image processing, multimedia and virtual reality, computer-aided design (CAD), database management systems (DBMS), spatio-temporal statistics, artificial intelligence, communications and Internet technologies amongst others.

GIS is extended from data organization to help in problem solving and success decision making. It goes beyond conventional spreadsheet and database tables to help discovering and visualizing new data patterns and relationships. GIS software makes it possible to undertake a sophisticated visual approach to data analysis. Such analysis would require

Journal of Engineering Sciences, Assiut University, Faculty of Engineering, Vol. 41, No. 4, July, 2013,E-mail address: jes@aun.edu.eg 
much effort if done by traditional methods. Statistical and spatial analysis has been greatly enhanced by the availability of sophisticated software.

This can be achieved through its unique way of classifying multifaceted, real-world data coming from different sources into map layers (themes) see figure 2-right. Each theme covers a single aspect of reality. They are then linked by spatially matching. Finally, querying and analyzing can be then made to produce new information and hypotheses. This is useful for the context of aggregated patient records.

\section{GIS for health services}

Health Geography can be divided into two categories:

-The geography of healthcare systems, which deals with the planning, management and delivery of suitable health services (ensuring among other things adequate patient access) after determining healthcare needs of the target community and service catchment zones.

-The geography of disease, which covers the exploration, description and modeling of the spatio-temporal (space-time) incidence of disease and related environmental phenomena, the detection and analysis of disease clusters and patterns, causality analysis and the generation of new disease hypotheses;

The true strength of GIS technology in health is in its applications in both two previous areas of healthcare geography, in the followings some of these applications:

- Hospital planning of new sites based on changing distribution of patients via analysis of population density for example site selection for health care facilities based on the analysis of the patient population for an area.

- Conducting network analysis to provide a basis for efficient routing: e.g. home health workers to their patients or estimating travel time of elder patients (or other patients) to health care facilities.

- Evaluating accessibility and barriers to health care delivery, e.g. access to hospitals with hi-technology equipment for the treatment of heart disease and other barriers to the delivery of services to special populations such as Child and Family Health Care.

- Examining the spatial distribution of health care facilities and providers, physicians (by specialty), hospitals, ambulatory care clinics, nursing homes, etc. This leads to identifying gaps in services and under served areas.

- Evaluating environmental risk factors and their implications for health: examples are lead exposure among children, the presence of high levels of hazardous materials, the contamination of drinking water or air, and other exposure risks.

- Conducting epidemiological studies, disease monitoring and management, e.g. pediatric Asthma, AIDS, tuberculosis, cancer etc. Also examining public health trends, e.g., low birth weight or infant mortality.

- Conducting diffusion analysis, or proximity analysis tracked over time: a series of maps taken at periodic intervals to analyze changes in the spatial distribution of certain diseases, or in health care demand or supply in a geographic area.

However, for geographic informatics to be one day a mainstream technology in the health sector like today's spreadsheet and database packages, many data

Journal of Engineering Sciences, Assiut University, Faculty of Engineering, Vol. 41, No. 4, July, 2013,E-mail address: jes@aun.edu.eg 
Ahmed Abdelhafiz, Mohamad Abdel-Samea, Gis for Health Services, pp. 1396 - 1405

availability/quality barriers still need to be overcome, as well as cultural and organisational barriers, including "spatial illiteracy" among healthcare workers, while making the tools cheaper and much easier to learn and use.

\section{Health facility planning}

Planning process is an accepted way to treat complex problems of resource allocation and decision making. The planning system has an important role in managing and controlling the development trends. In today's technology driven environment, one can confirm that "failure to plan is planning to fail". Hospitals and healthcare services have been found to be areas of remedies for health related problems. They have been described as the most complex of building types, providing wide range of services and other fundamental units, such as diagnostic, treatment, laboratory, emergency and surgery rooms. Also hospital functions such as food or bed-related function.

Healthcare management and systems help hospitals to save lives, time, and money when the emergency strikes. This can be achieved through providing operations managers and healthcare administrators with the understanding and the tools needed for the accessible resources. Implementation of GIS is the main tool to make a healthcare plan. GIS in healthcare facilities planning can improve the result based on quality of planning process. It provides the ability to store and display maps and associated information from various sources. Therefore GIS is able to support the healthcare planning process in terms of input, storage, manipulation, analysis of data useful in planning, decision making and implementation. It is a powerful tool which helps the user to view the different scenarios so that the best strategy may be chosen for planning development. The use of GIS in healthcare planning can develop database for both data attributes and spatial data.

Health planners keep analyzing the changes that occur on health care demand. Geographical research into healthcare services can also help identifying inequities in health service delivery between classes and regions, and in the efficient allocation and monitoring of scarce healthcare resources. Health geography plays a vital role in public health surveillance, including the design and monitoring of the implementation of health interventions and disease prevention strategies. This include allocating healthcare staff by region based on actual needs, and assisting in determining the best location and specifications for new healthcare facilities and in planning extensions to existing ones. The integration of Geographical Information System has provided a tool which can contribute to clearer understanding of real planning problems as well as prescriptive planning scenarios to enhance the quality of urban planning and management.

\section{Appling GIS Assiut health services}

Government of Egypt has to implement a wide range of legislative reforms. Health reform is currently very urgent. The main objectives of health reform are the best attainable, average level of goodness on the primary health care level and the smallest feasible differences among individuals and groups (fairness). Also to identify the main areas of potential primary health care gain and review the existing situation of the different

Journal of Engineering Sciences, Assiut University, Faculty of Engineering, Vol. 41, No. 4, July, 2013, E-mail address: jes@aun.edu.eg 
1402

Ahmed Abdelhafiz, Mohamad Abdel-Samea, Gis for Health Services, pp. 1396 - 1405

health services against planning standards guidelines. Health reform has to detect the unserviced areas according to the guidelines of Ministry of Health and Population in Egypt "MOHP" 2012. These guidelines are; a Primary Health Care "PHC" unit serves 20000 persons and area of $2.5 \mathrm{~km}$ radius. Definitions of a primary health care and a primary health centre can be reviewed in the World Health Organization WHO 1978.

Assiut governorate is one of rural areas in Egypt. It is located in the Upper Egypt at the west of the Nile valley to the south of Cairo with distance of about $400 \mathrm{~km}$. It stretches for about $120 \mathrm{~km}$ along the banks of the Nile. The total area occupies about 25,926 km2; the occupied area is about $1558 \mathrm{~km} 2$. The percentage to total area of Egypt is $2.6 \%$. Assiut governorate has an estimated population of 3.8 million in year 2012 (male $51.21 \%$; female $48.79 \%$ ). The percentage to the whole population of Egypt is $4.3 \%$. The population growth rate was estimated to be $2.6 \%$ per year. The age distributions of Assiut governorate indicates that Assiut has youth age structure distributions because the age period from 15 to 64 represents $53.7 \%$ and the age period of $(0-14)$ and (+65) represent $46.3 \%$. (Assiut governorate on Wikipedia)

The capital of Assiut Governorate is Assiut city. The modern city is located at $27^{\circ} 11^{\prime} 00^{\prime \prime} \mathrm{N} 31^{\circ} 10^{\prime} 00^{\prime \prime} \mathrm{E}$, while the ancient city is located at $27^{\circ} 10^{\prime} 00^{\prime \prime} \mathrm{N} 31^{\circ} 08^{\prime} 00^{\prime \prime} \mathrm{E}$. The city of Assiut has almost 400,000 inhabitants. The city of Assiut is situated between two mountain ranges of about $600 \mathrm{~m}$ height. Its elevation is about $55 \mathrm{~m}$ above sea level.

The present work deals with healthcare facilities in Assiut city. This part will concentrate more on this issue and explain how GIS is used to analyze accessibility to hospitals in Assiut City, Egypt. The main objectives are to determine serviced and un-serviced areas by health facilities. Figure 3 shows Assiut city roads and the available public hospitals in Arc map.

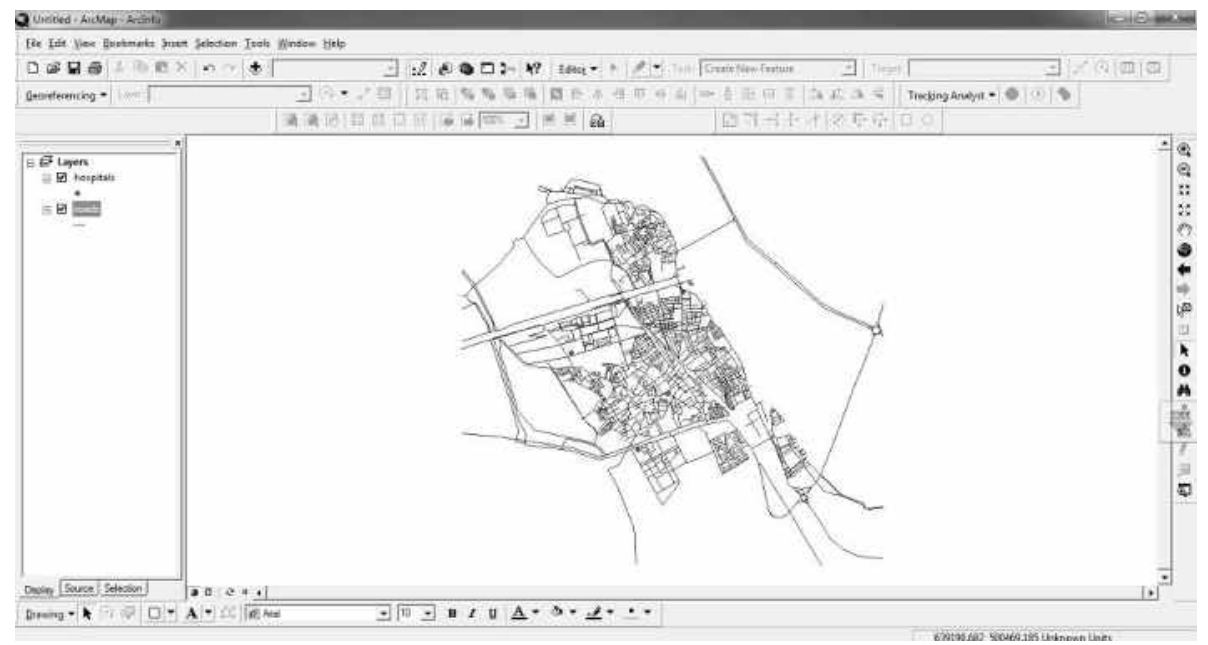

Fig. 3. Streets and hospitals of Assiut city in Arc map

The spatial and attribute data were collected from maps and Assiut Health Authority. The different infrastructures and landmarks are digitized from Google satellite images using

Journal of Engineering Sciences, Assiut University, Faculty of Engineering, Vol. 41, No. 4, July, 2013,E-mail address: jes@aun.edu.eg 
Ahmed Abdelhafiz, Mohamad Abdel-Samea, Gis for Health Services, pp. 1396 - 1405

AutoCAD and Arc/map. The health facilities overall Assiut city are located on a street map. Hospitals specialized in specific dieses are not considered.

There are three important factors that affect the level of accessibility in any facility location. These are the capacity of the facility, the amount of demand for such facility, and the transporting network that communicate such demand to the relevant capacity. According to the MOHP guidelines the PHC units must satisfy the following parameters which are the serviced distance is within $2.5 \mathrm{~km}$, and (PHC) unit's power equal to 20000 population, or 2.5 beds per 1000 persons.

Figure 4 shows the coverage detection of the serviced and un-serviced areas according to the first guideline of MOHP (PHC unit serves area of $2.5 \mathrm{~km}$ radius). The figure shows that about $25 \%$ of the total area is un-serviced by health care facilities. These areas are Alnazla and Alwelidea regions which are low socio-economic regions. Alwelidea region which has high population density is located in the north-east of the map (U1). The other region "Alnazla" is located in the south-east of the map (U2).

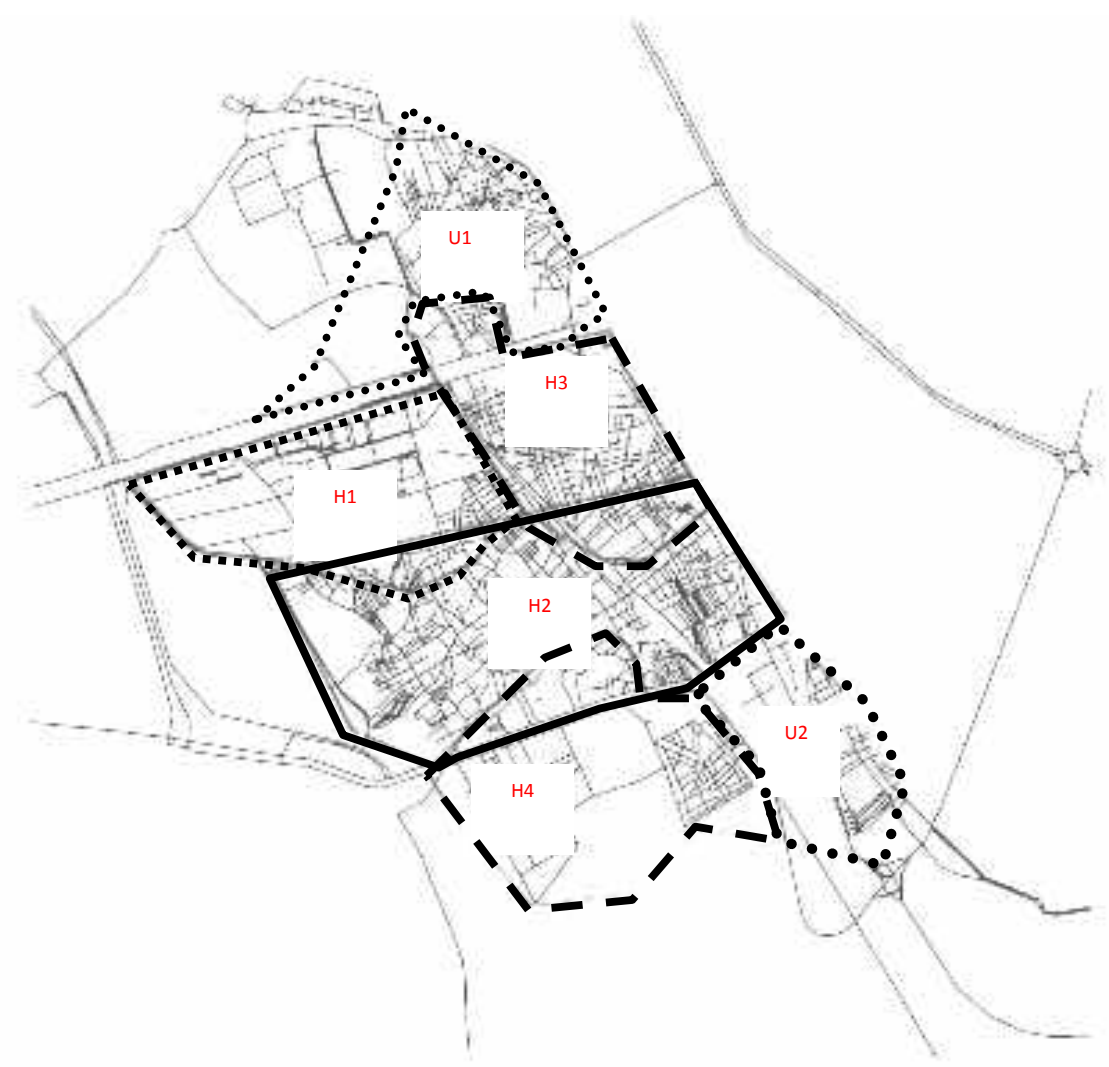

Fig. 4. Serviced and un-serviced areas in Assuit city.

Journal of Engineering Sciences, Assiut University, Faculty of Engineering, Vol. 41, No. 4, July, 2013,E-mail address: jes@aun.edu.eg 
1404

Ahmed Abdelhafiz, Mohamad Abdel-Samea, Gis for Health Services, pp. 1396 - 1405

It is clear from the figure that the four hospitals (H1 to H4) can fulfill the $2.5 \mathrm{~km}$ radius criteria if the hospitals are correctly distributed. Three hospitals are located on the ring road of the city. This location offers good accessibility especially in the rush hours, which is considered as a good point in planning. The forth one $(\mathrm{H} 2)$ is in the city centre. Its location from the theoretical point of view is considered positive point. On the other hand, because of the high density of traffic, the accessibility to that hospital in the city center is practically difficult.

The second guideline which is (PHC) unit's power equal to 20000 population is not fulfilled. According to this guideline, the four hospitals in Assiut city could cover 80000 persons only, where Assiut estimated number of population is 400,000 persons.

The total demand of Assiut population $(400,000)$ according to the criteria of 2.5 beds per 1000 persons is about 1000 beds. H1 which is Assiut university hospital has about 1694 bed. H2, H3 and H4 have 219, 291 and 141 beds respectively in order i.e. 651 beds as a total number of the three hospitals. The demand is then covered only with Assiut university hospital which is located in the university campus.

Assiut University Hospital is considered one of the biggest university hospitals in Egypt and it is the core medical center in Upper Egypt. It serves about twenty millions of population from all governorates of Upper Egypt not only in complex cases but also for ordinary cases. So, its beds can't be considered for Assiut city only. If the three other hospitals are only considered then the available number of beds (651) are not enough to meet the criteria. H1 has to share with (349) beds to fulfill the guidelines.

\section{Conclusions}

1- GIS is a powerful tool for evaluating healthcare facility planning problems. It is used here to detect serviced and un-serviced regions in Assiut city. The spatial analysis here shows new view for the current situation that can't be seen without using such type of analysis.

2- International standards and guidelines to check healthcare services are based on two points which are; a Primary Health Care "PHC" unit should serve a certain number of persons and, a PHC should cover an area of a certain radius.

The Ministry of Health and Population "MOHP" in Egypt considers the international guidelines within the international standards. A "PHC" unit in Egypt should serve 20000 persons and area of $2.5 \mathrm{~km}$ radius. According to the "MOHP"; the demand of Assiut city doesn't meet the guidelines in both the two international points as follows:

a) About $25 \%$ of the total area of Assiut city is un-serviced.

b) About $80 \%$ of the total number of population is un-serviced. As four PHC should serve 80000 persons only. In real, they serve at least the estimated number of population for Assiut city (400,000 persons). The total number of beds available serves Assiut city as well as all Upper Egypt governorates.

3- Upper Egypt governorates need further steps in planning for new health care facilities considering the MOHP guidelines as most of the population are pushed to travel tens to hundreds of kilometers to access the required health services from large medical centers like Assiut University hospital and similar centers in Cairo, in addition to the shortage of the services when accessing due to the large number of patients.

Journal of Engineering Sciences, Assiut University, Faculty of Engineering, Vol. 41, No. 4, July, 2013,E-mail address: jes@aun.edu.eg 
Ahmed Abdelhafiz, Mohamad Abdel-Samea, Gis for Health Services, pp. 1396 - 1405

4- Egypt has to give more attention for implementing GIS in health care reform strategy by providing hardware, software and training courses for planners which will be reflected on better health care service planning.

\section{References}

[1] Adeyemo, D.O., 2005. Local Government and Health Care delivery in Nigeria: A Case study. Journal of Human Ecology, 2, 149 - 160.

[2] HIGGS, G., 2004. A Literature Review of the Use of GIS-Based Measures of Access to Health Care Services. Health Services \& Outcomes Research Methodology 5: 119-139.

[3] Huang X. Y., Ma J. S., and Tang Q., "Geographic Information System Conspectus," Higher Education Press, Beijing, 2001.

[4] Map World of GIS, http://www.mapsofworld.com/gis/components.html.

[5] Reynolds H., "An Introduction To Geographical Information System [GIS]," www.badpets.net, 2011.

[6] Selamat H., Selamat A., Othman S., Shamsuddin N, and Zukepli5 N., 2012. A review on Geographical Information System (GIS) in Town Planning: Malaysia Experience. Geoinformatica: An International Journal (GIIJ), Volume (2) : Issue (2).

[7] Tang G. A., and Zhao M. D., "Geographic Information System," Science Publishing House, Beijing, 2000.

[8] World Health Organization (WHO). Declaration of Alma-Ata. Adopted at the International Conference on Primary Health Care, Alma-Ata, USSR, 6-12 September 1978.

[9] Yaakub A., Ludin A. N. M, Sulaiman S. and Bajuri H., " GIS in Urban Planning and Management: Malaysiam Experience," International Symposium \& Exhibition on Geoinformatics, Geospatial Solutions for Managing the Borderless World, pp. 1-13, 2005.

\section{أستخدام نظم المعلومات الجغرافية فى الصحة}

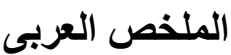

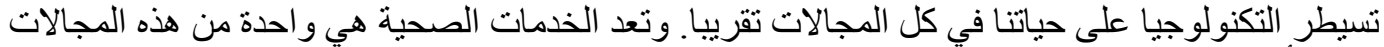

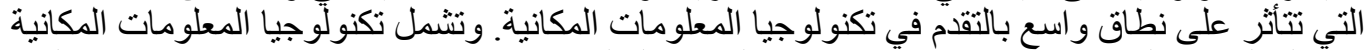

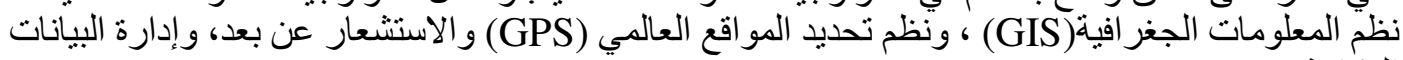
المكانية.

تساعد نظم المعلومات الجغر افية المخططين في تخطيط ومتابعة مر افق الرعاية الصحية المختلفة. وذلك يمكن

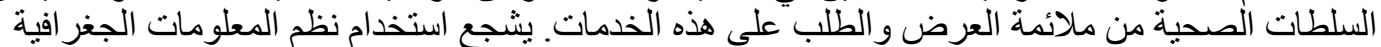

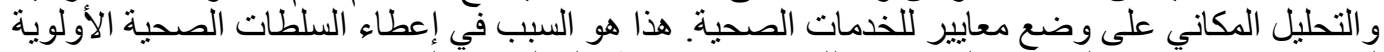

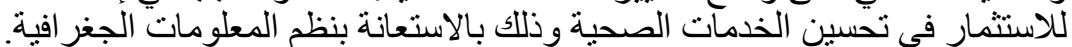

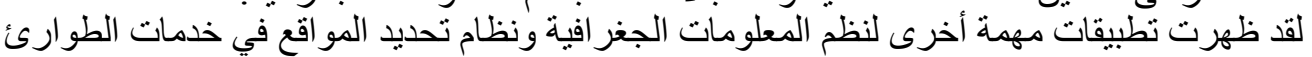

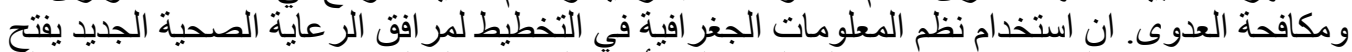

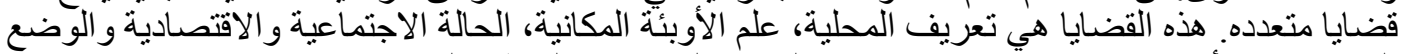

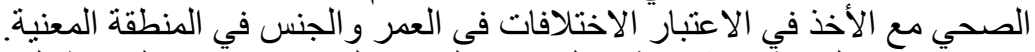

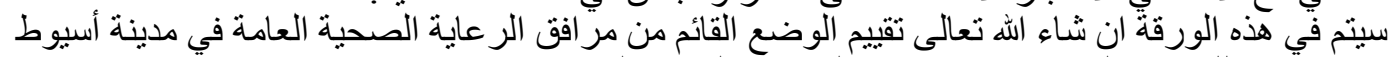

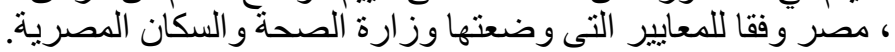

Journal of Engineering Sciences, Assiut University, Faculty of Engineering, Vol. 41, No. 4, July, 2013,E-mail address: jes@aun.edu.eg 